\title{
Compliance and Creativity: Dilemmas for University Governance
}

\author{
PETER SCOTT \\ UCL Institute of Education, 20 Bedford Way, London WC1H 0AL, UK. \\ Email: p.scott@ucl.ac.uk
}

\begin{abstract}
The contemporary university is subject to two, apparently contradictory, forces. The first is the drive towards the modernisation of its governance and management, often in ways that reflect corporate structures more familiar in the private sector (and other parts of the reformed public sector). This drive has been accompanied by the growth of performance management, both of institutions and individual teachers and researchers; the more prescriptive identification of goals and targets (at the expense, perhaps, of traditional notions of autonomy and academic freedom); and more explicit - and intrusive? - forms of audit, accountability and evaluation. The other force is the development of new modes of learning, a more open curriculum and more distributed patterns of research. Examples include the popularity of (technology-enhanced) self-directed learning, the growth of massive open online courses (MOOCs), the spread of open-source publication and greater emphasis on the impact and application of research. Both forces reflect deeprooted changes in the nature of modern higher education and research systems, and it would be misleading to see them as always or inevitably in conflict. However, they do pose new dilemmas about how to maintain an appropriate balance between the necessary management of the large, complex and heterogeneous organisations that modern universities have become and their capacity for innovation and creativity.
\end{abstract}

\section{Introduction}

University governance is a complex field. It can be interpreted in a narrow sense, focusing on the formal 'government' of higher education systems and institutions, or in a wider sense, emphasising 'governance' to embrace not only formal legal and administrative regimes but also how decisions are taken and implemented (and so including what is often labelled 'management') and also on the informal influences that impact on governance and management. There are also many layers of university governance. New forms of 'global' governance are emerging, the impact of international organisations such as the World Bank or the Organisation for Economic 
Cooperation and Development (OECD), and these are being reinforced by increasingly powerful regional influences (the best example perhaps is the impact of the Bologna process and of successive 'Framework' research programmes in Europe). ${ }^{1,2}$ The heartland of university governance remains at national, or State, level, where higher education systems are coordinated, steered and - increasingly - regulated, and at institutional level where the detailed strategies and priorities of individual universities are determined. But sub-institutional levels of university governance are also important, not only in the context of the relative autonomy of Faculties, Departments and Institutes but also in the context of quasi-commercial activities such as science and technology parks, and even wholly owned university companies. Although the focus of this contribution will be on the 'heartland', state-level and (in particular) institutional governance, the wider context should not be forgotten.

The title of this article, 'compliance and creativity: dilemmas for university governance', implies that there is some tension, contradiction even, between on the one hand the pressures on universities to comply - in many different ways (to formal audit procedures, to broader quality and assessment instruments, to new accountability regimes whether mandated by State authorities or created by new 'market' [or quasimarket] mechanisms) - and on the other hand the obligation of universities to promote creativity, whether in the learning of first-year students or the production of world-class research. Indeed there may be a temptation to replace the 'and' with an 'or'. But that would be going too far if it was taken to mean there was a zero-sum game between 'compliance' and 'creativity' - the more compliant universities are, the more limited their capacity to act creatively. However, the potential tensions need to be acknowledged between the development of more corporate forms of university governance, of which the need for 'compliance' is a major driver, and both the historical obligation of universities to promote 'creativity' and the emergence of more 'open' knowledge production regimes.

This article addresses three topics. The first is a discussion of the development of these new, and more corporate, forms of university governance, and in particular the impact of the growth of a stronger compliance culture in higher education. The second is an examination of both the historical obligation of universities to promote 'creativity' and the emergence of these new and more 'open' knowledge production systems, which are closely linked with processes of 'innovation', again broadly defined. The third and final topic is an analysis of the complex relationship between more sophisticated governance and management systems on the one hand and, on the other, the increasingly open intellectual and scientific agendas characteristic of contemporary higher education and research, and also an exploration of the ways in which any tensions between them can best be handled. How can the synergies be maximised, and the contradictions minimised?

\section{Corporate Governance}

The development of more corporate systems of university governance is both a dominant and a complex phenomenon. 
It is a dominant phenomenon because its major features are pervasive, and can be observed across different types of university and also across different higher education systems with different traditions, organisational patterns and administrative and funding regimes. To take some obvious examples:

- In many European universities there has been a shift from elected to appointed Rectors (and, even when they have continued to be elected, their office has taken on more of a quasi-executive function). The traditional idea of a Rector exercising titular and symbolic, rather than managerial, authority, is in retreat;

- This shift has been accompanied by the development of a senior management team, or Rectorate, composed of other senior academic, and professional, managers who are now seen as having a corporate responsibility for managing the institution. This has been reflected in the growth of managerial and administrative posts as a proportion of all university staff;

- University boards have taken on more of the characteristics of corporate boards. In some countries, small boards, perhaps of only three people (the chairman of the board, the Rector and the University Director), effectively manage the university. In others, boards have more members but are likely to include more 'external' stakeholders. Larger boards, or councils, with more elected members, and traditional Senates have been sidelined;

- Often the relationship between universities and their constituent units, especially traditional Faculties, has been recast. Although budgets (and operational responsibilities) may have been devolved, these units no longer enjoy semi-autonomous status but are more subordinate to university-wide policies;

These are just a few examples of the changes that have taken place in many European countries. Although the degree of 'corporatisation' of university governance still varies, there seems to be little doubt about the overall direction-of-travel.

However, the development of these more corporate forms of university governance is a complex phenomenon because it has multiple causes. These causes can perhaps best be grouped into 'internal', or endogenous, drivers that reflect the more fundamental changes in the nature of universities as organisations (and of the nature and purpose of higher education systems) in the twenty-first century; and 'external', or exogenous, drivers that reflect changes in political economy (and also in ideology). It is important to distinguish between these two groups of drivers, because some of the forces promoting the 'corporatisation' of university governance are not only inevitable but also necessary, because they reflect the deeper and more extended mission of contemporary universities, while others are more fairly regarded perhaps as quasi-alien intrusions into the traditional character, and essential ethos, of universities. This is not always easy because 'internal' and 'external' drivers, in practice, tend to overlap. Nevertheless it is an important distinction, especially so in the context of creativity and innovation. 
There are few more theoretical models of governance that focus primarily on higher education. Most seek to use the general characteristics of the so-called 'new public management' (NPM) which has been applied to many publicly funded services in the United States and Europe since the 1980s. ${ }^{3}$ NPM has perhaps become too broad - and loose? - a category and is now (mis?) used to describe a wide range of public reforms, which in practice have less in common than this generic label may suggest. One of the most interesting attempts to apply NPM to the governance of higher education, identified, at institutional level, five distinct elements - state regulation (including funding); stakeholder involvement (and guidance); academic selfgovernment; managerial competences; and competition (often within contrived 'internal markets'). The assumption is that some of these elements will become less influential - state funding (if not state regulation) and academic self-government perhaps - while others will become more influential - for example, managerial competences or stakeholder involvement (and certainly competition). ${ }^{4}$

\section{'Internal' Drivers}

The dominant 'internal' driver is the massification of higher education, which has been at work for at least two generations (and, of course, reflects wider changes in society and the economy, and, in particular, rising aspirations among individuals and in society, so it cannot be described as entirely an 'internal' phenomena). ${ }^{5,6}$ Massification has had a number of effects, all of which have tended to promote more 'corporate' styles of governance.

(1) The first, most banal and so often overlooked, is simply that universities have become much larger - which has meant they cannot be governed and managed according to less formal, collegial and consensual, rules, but must establish more explicit (and elaborate?) systems of governance and management. This requirement applies not only to the internal organisation of universities; universities now also have more important 'footprints' in their communities and cities (and have heightened impacts on housing, traffic, the environment, artistic and cultural institutions).

(2) The second is that universities have become more heterogeneous - in a number of different ways:

- Universities have become more heterogeneous because their students are now drawn from a much larger and more diverse social base. Sometimes this is seen almost exclusively in terms of the enrolment of students from, broadly speaking, non-elite social groups. But just as important perhaps have been important cultural shifts that have affected all students, elite and non-elite;

- They have also become more heterogeneous in terms of their range of disciplines and teaching styles. More professional and vocational programmes have been introduced into higher education, even when 
the traditional distinction between 'academic' (or 'scientific') universities and other higher professional schools has been maintained. Equally important has been the introduction of learning cultures that reflect new cultural habits and technological possibilities. The increasing roles played by online learning and social media may be particularly significant;

- In some countries, and institutions, this has been further enhanced by the increasing significance of 'entrepreneurial' activities - such as business education (including 'executive' and in-company courses), continuing professional development programmes, applied research, consultancy and technology transfer - sometimes through the medium of subsidiary companies (which may be organised along purely commercial lines).

With the exception perhaps of the last, where entrepreneurial activities can become over-commercialised, few object to these extensions of the role of universities. But they clearly require a significant upgrading of management capacity, and changes in governance arrangements. This growth of heterogeneity, like the scaling up of institutions and systems, has emphasised the importance of more structured governance and management regimes.

\section{'External' Drivers}

In addition to these (largely) 'internal' drivers - although 'structural' would perhaps be a more accurate label - there are a large number of 'external' drivers of the increasing 'corporatisation' of university governance. These are more likely to be characterised as negative or hostile. They include:

- The rise of the 'audit society', so skilfully analysed by Michael Power and other scholars. ${ }^{7}$ This has many sources. One certainly is the wider erosion of trust, especially perhaps in the natural authority of traditional institutions such as universities but now extending to an increasing scepticism about 'expertise'. Informal assurances now have been reinforced by more formal systems of guarantee. This is reflected in our perceptions of 'risks', their apparent proliferation and our determination to manage them. A second is simply that more sophisticated data systems now allow more exact scrutiny of performance. We can measure it - so we do. A third is that, like most other organisations, universities have to comply with an increasing number of regulations - some of which are generic, on employment or safety for example; some of which are more specific, like research ethics and integrity. The implications for universities are, first, that they must develop their own more elaborate data systems to ensure compliance; and, secondly, more management information is available to allow more effective 'steering' of institutional strategy and performance. 
- Closely linked to the impact of the 'audit society' is the growth of new forms of accountability that have sometimes been difficult to reconcile with traditional ideas of institutional autonomy and academic freedom. ${ }^{8,9}$ In some countries, where 'marketisation' policies have been actively (and aggressively) pursued by introducing, or increasing, student fees, accountability has been framed in terms of 'satisfying' 'customers' (i.e. students). Both ideas - 'satisfaction' and 'customers' - of course are problematic and even contested in the context of higher education. But there are other, less controversial, forms of accountability. For example, many universities act purposively to 'engage' - with their students, users of their research, their communities, even with the wider public. But these also imply heightened degrees of accountability. The increasing popularity of a discourse centred on 'world-class' universities, often derived from competitively generated league tables, has a similar effect. The impact on universities is twofold. They are required to develop new management capacity to respond - notably in terms of branding, marketing and customer relations. But those responsible for their governance are also furnished with new data and are required to make strategic choices based on, and assess performance according to, these data.

- A third 'external' driver is the decisions taken in many European countries to enhance the organisational autonomy of their universities, typically by transferring ownership of buildings from the State to individual universities and often by making universities the legal employers of their staff. ${ }^{9}$ This has sometimes been characterised, in hostile terms, as amounting to 'privatisation'. Often it has been accompanied by new funding regimes under which public funding is allocated by contracts according to performance (and, perhaps coincidentally because of post-2008 'austerity' policies pursued by most Governments, by budget cuts). But the intention has been to allow universities greater freedom to determine their own futures, at any rate in terms of their operational management. ${ }^{10}$ It is not a coincidence, of course, that this devolution of administrative responsibilities has gone hand-in-hand with the growth of 'compliance'. Universities, like many other (public) institutions, have found that the so-called regulatory state can be just as intrusive, and controlling, as the welfare state. ${ }^{11}$ But, whatever view is taken, this devolution of responsibilities has had important implications for university governance, encouraging the development of more sophisticated and, arguably, more 'corporate' forms of governance and management.

In summary there has been a range of 'internal' and 'external' drivers of the corporatisation of university governance. They are not uniformly unwelcome; indeed, several reflect the need to enhance the capacity of universities to meet their social obligations and fulfil the wider mission that is at the heart of mass higher education systems and, in particular, to promote their creative and innovative capacities. Nor are these drivers consistent; some reflect a desire to control universities, and 
subordinate them to political agendas, while others are designed to liberalise their operations and free them from unnecessary bureaucratic controls (even if the effect has been to stimulate the growth of their own bureaucratic systems). But their overall impact has been to encourage the development of more corporate forms of university governance - which have the potential to restrict their creativity and inhibit rather than encourage their capacity for innovation.

\section{'Open' Learning and Research}

The second topic in this article is the development of more 'open' knowledge systems in terms of curriculum, learning and teaching practice and also delivery modes; and also in terms of research and knowledge generation. This 'openness' is an important factor in stimulating creativity and promoting innovation - but, arguably, it has been made more difficult to realise within the tighter corporate structures that now characterise university governance and management (and which have just been discussed). This shift towards more 'open' knowledge systems is considered under four headings: the traditional commitment of universities to critical enquiry, both in teaching and research; the development of new cultures, and methodologies, of learning in contemporary higher education; the growth of new patterns of knowledge production (some of which are more focused and concentrated and others more widely distributed); and, finally, the role played by higher education and research in contemporary societies.

\section{Critical Enquiry}

Traditionally, universities have always operated on the frontiers of the (currently) knowable - and also thinkable. A categorical distinction between a university education and preceding levels of education has always been its commitment to critical enquiry, by subjecting existing knowledge to rational (and even sceptical) interrogation. Somewhat unfairly perhaps, this has occasionally been taken to imply the lack of a need for criticality in school education. Such criticality has sometimes been difficult to observe within the structured and linear curriculum characteristic of many disciplines (in particular, perhaps, professional and vocational disciplines that aim to initiate students into specific professional cultures and train them in well-tested expert skills). It has even been argued that this critical ideal is difficult to reconcile with the realities of mass higher education systems. Nevertheless it remains a hallmark of higher education at its best, a defining and foundational characteristic. The aim remains to empower lifelong learners, with the habits and skills needed constantly to renew themselves intellectually, rather than the 'terminal' graduate. ${ }^{12}$

In the case of research, the emphasis on criticality, and scepticism, is even greater. At its root is the Socratic 'I know that I do not know', and a core belief that all knowledge is provisional. This is true whether the key method is seen to be verification, as Bacon (and, to some degree, Hume) believed, or falsification, as Popper powerfully asserted. It is also true even in the case of essentially incremental 'normal science' (to adopt Kuhn's terminology), which is how the bulk of research is best described. Arguably, criticality 
and scepticism are even more essential for 'normal science' than they are for fundamental breakthroughs, or 'paradigm shifts', which clearly depend on leaps of imagination that may transcend the merely rational. In both teaching and research, therefore, universities have always been committed to 'open frontiers'. The development of the university as an institution is a story of how this commitment has been pursued within organisational structures that are minimally constraining.

\section{New Forms of Learning}

This 'openness' has been enhanced by more recent developments - fashions, critics may suggest - in student learning and the university curriculum. For example, in many professional disciplines the emphasis has switched from a dominant focus on the codification and transmission of expert knowledge to the development of 'problem solving' skills (and habits) by students in realistic social settings. Most medical schools now teach future doctors through some form of 'problem solving' curriculum. The curriculum in business schools places special emphasis on the analysis of realworld 'case studies'. There are many other examples. In other disciplines students are encouraged to be engaged, and even activist, participants - for example, in human rights or women's studies, but also in law or history. This engagement, and activism, have created a more 'open' (and contested) curriculum, which has led some critics to deplore the danger that relativistic ideas may displace scientific rigour (and, a more recent concern, that 'politically correct' ideologies may prevail). More generally across higher education, although students have always been recognised as partners in their own learning, there is greater emphasis on peer learning and the co-production of knowledge. This has opened up new, but creative, uncertainties.

How these new forms of student learning and developments in the curriculum can be managed within universities that are increasingly required to demonstrate the 'quality' of their courses and also their (comparative) performance raises difficult issues. On the one hand, these more 'open' forms cannot easily be contained within managed procedures and structures without constraint. On the other, their essential fluidity may demand a framework of control that was less essential in the case of traditional disciplines and traditional forms of student learning. One example is the pressure to (over?) specify 'learning outcomes'. The emergence of massive open online courses (MOOCs) illustrates this tension. To enable them to be 'open' to all, and to 'students' who have not been socialised within traditional academic structures, they must be coherently structured and highly specified - even if these 'students' then use the material provided by MOOCs in their own individual ways.

\section{New Patterns of Knowledge Production}

The development of research in universities displays the same paradox. On the one hand, research has clearly become a more managed activity. In order to promote its quality (as measured through the proliferating number of formal assessment systems, and also by citations and other indicators of esteem), to increase the productivity of researchers, to enhance institutional reputations and to support national research and 
development strategies, the freedom of individual researchers has been sharply constrained. ${ }^{13}$ There is also a growing trend to concentrate research funding in a restricted number of 'centres of excellence' to increase the competitiveness of national higher education and research systems. In the United Kingdom, the Research Excellence Framework (REF), in Germany the Excellenz initiative, and in France the development of clusters of institutes and universities into pôles are all examples of this trend towards concentration.

On the other hand, there is persuasive evidence that new - and more 'open' systems of knowledge production are developing. Knowledge is now generated by much more diverse groups of 'researchers', not all of whom are to be found in traditional academic settings, in more heterogeneous contexts, of which the university is only one (and not always the most important). That knowledge may be embodied in practice (real-world projects, socio-economic contexts) rather than simply codified in conventional scientific forms (articles, patents, books). Its quality may also be assured by more varied and complex means than traditional forms of peer review. These changes have been summed up under the label of 'Mode 2' knowledge, although the usefulness of that label has been contested. ${ }^{14,15}$ They open up intriguing questions about alternative approaches to the validation and institutionalisation of knowledge.

These two trends in research - concentration and diffusion - seem at first sight to be based on contradictory principles. The former appears to be based on a relatively 'closed' system based on settled and conventionally determined 'scientific communities'; the latter appears to be permeable, highly reflexive and difficult to encompass (let alone manage). Yet both are real, and in practice they must be reconciled.

\section{Universities in the 21st Century}

All universities, to some degree, are 'open' universities under contemporary conditions. Their student intakes are no longer drawn predominantly from social (and academic) elites but from whole communities (even if important social groups remain disadvantaged and even excluded; mass higher education has not yet been displaced by universal higher education, and indeed may never be). Their intellectual and scientific functions, both in teaching and research, are no longer constrained within traditional notions of academic and professional culture but have spilled out to affect, and be affected by, wider social and cultural forces. Above all, universities are now 'engaged' in their communities in a myriad of ways, new as well as old. ${ }^{16,17}$

In the twenty-first century, they have also become key nodes of creativity, not simply in terms of their traditional responsibility as agents of critical enquiry or scientific discovery or even of 'impactful' research but also of social, cultural and artistic experimentation. The optimistic view is that university cities are at the cutting edge of social change and economic advance, providing environments in which creativity and innovation can flourish. ${ }^{18}$ A more negative view simply emphasises their 'apartness', as demonstrated by social (and sexual) norms, patterns of employment, and political allegiances. They appear to represent elite, metropolitan and 
internationalist views that other sections of society may find uncongenial. Either way, universities and their cities are characterised by new degrees of 'openness'.

\section{Conclusion: Reconciling the Corporate and the Creative}

How can these apparently contradictory trends - towards the corporatisation of university governance (and, arguably, the 'closure' of organisational forms) and towards greater 'openness' in learning, research and the positioning of universities in the twenty-first century - be reconciled?

First, it is important to recognise that the contradictions between them may be more apparent than real. Both arise from the far-reaching changes that have taken place in the role of universities in society, their changing organisational characteristics, their extended missions and also from equally far-reaching changes in the constitution of knowledge and skills in advanced societies and economies, in terms of both student learning and the curriculum and of research. New modes of compliance reflect attempts to operationalise the embedding of universities in the knowledge society and their role in social change and liberal and democratic culture. New patterns of governance and management have been primarily established to create the structures within which critical and scientific enquiry can be promoted under contemporary conditions.

However, it would be naive to deny the emergence of new tensions. At the state level there are mixed messages. On the one hand, in many countries, substantial progress has been made in freeing universities from bureaucratic controls. Individual institutions are now able to match their operational procedures (for example, in terms of internal funding allocation or staff contracts) to their academic ambitions. On the other hand, not only has state funding often been reduced (forcing institutions to seek alternative sources of funding, which may have more conditions attached than public funding) but Governments have tended to recast their relationship with universities in contractual or regulatory terms. They have redefined their role as that of over-mighty 'contractor', on behalf of students and citizens, and also of the regulator of semiprivatised institutions (and even private, for-profit, institutions as well). Although there are differences of emphasis in different countries (with English higher education being the most 'market-like' in Europe), the direction of travel seems clear. Efforts to articulate, and operationalise, the concept of the 'social dimension', as celebrated in successive Bologna communiques and similar statements of principle, which might serve as a brake on marketisation, have enjoyed limited success.

As a result, an overall balance sheet is difficult to draw up; the gains in terms of freedom from bureaucratic controls may have been outweighed by the losses in terms of the need to meet new contractual requirements and also the increasing burden of compliance. In detail, much of this compliance is necessary and even beneficial, but its overall effect has been to widen and deepen the accountability of universities to their societies (in practice, the state bureaucracies from which they have been supposedly 'freed'). Although in a different way, the 'regulatory state' of the twenty-first century is arguably more intrusive than the 'welfare state' (or 'social state') of the 
twentieth century. The accumulation of compliance has also been magnified by the pervasive discourse of 'modernisation', championed by international organisations such as the OECD and enthusiastically adopted by many Governments, which has perhaps had a chilling effect on autonomy and so the possibilities for creativity. The parallel and associated discourse of 'excellence' (or 'world-classness') may have a similar effect. The policy instruments designed to promote 'excellence', designed to increase the quality and productivity of research or 'drive up' standards of teaching, tend to impose standardised (and conventional) definitions of 'excellence', which may accidentally discriminate against (unexpected or unwelcome) novelty, innovation and creativity.

One remedy would be to encourage all Governments to conduct audits of their overall impact of all their policies - compliance and regulation, strategic 'steering' to support national priorities, initiatives to promote a stronger 'quality culture' in universities or to focus resources on those with the potential to achieve 'excellence' on the autonomy of universities and, more crucially still, on the freedom enjoyed by teachers and researchers. As has already been indicated, taken separately many (even most) of these policies are well designed with the best intentions. But there have been few systematic attempts to assess their overall impact.

At the institutional level, the challenge is to maximise the synergies, and minimise the tensions and contradictions, between the more corporate forms of university governance that are developing (again, largely for good reasons) and the nurturing of creativity in higher education and research. There are several ways in which this can be done. One is to ensure that corporate governance is suffused with, and subordinated to, academic leadership. The tradition that Rectors, Presidents and Vice-Chancellors are drawn - with very few exceptions - from the professoriate should be defended. There is evidence to suggest that the most successful research universities tend to be led by active, and distinguished, scholars and scientists. ${ }^{19}$ A second is to avoid too sharp a distinction being created between the academic staff and the 'administration' - and, particularly, to discourage the emergence of a sharply delineated 'class' of academic managers. To enable academics to take on management roles without completely abandoning their scholarly or scientific ambitions, measures will be needed to mitigate the inevitable (and, largely, desirable) specialisation, and professionalisation, of teaching and research roles in universities. A third method is to protect and strengthen academic governance, by preventing the erosion of the authority and influence of Senates (and senior academic leaders): and also to ensure that the constitution of the formal organs of university government reflect the importance of academic governance and also respect, at least in part, principles of democratic representation and do not become over-dominated by notions of professional and corporate expertise.

The tension and even contradiction between 'compliance' and 'creativity' announced in the title of this article are not inevitable. A well-governed and wellmanaged university can provide an environment in which creativity and innovation flourish - just as a sensible system of coordination at State level can allow institutions to focus on their strengths and realise their potential without unnecessarily restricting 
their autonomy. Indeed, well-governed and well-managed institutions, and sensible systems of coordination, are essential to the healthy functioning of universities in the twenty-first century because of the complexity and heterogeneity of their missions. But there are clearly dangers associated with the creeping corporatisation of universities as organisations, as there are of discourses of 'modernisation'. It is only by acknowledging these dangers and recognising the need for balanced solutions that creativity can be nurtured and strengthened.

\section{References}

1. R. King (2009) Governing Universities Globally: Organisation, Regulation and Rankings (Cheltenham: Edward Elgar).

2. E. Voegtle (2014) Higher Education Policy Convergence and the Bologna Process: A Cross-National Study (London: Palgrave Macmillan).

3. E. Ferlie, C. Musselin and G. Andresani (Eds) (2009) The governance of higher education systems: a public management perspective. In: C. Paradeise, E. Reale, I. Bleiklie and E. Ferlie (Eds.), University Governance: Western European Comparative Perspectives (Dordrecht: Springer).

4. H. de Boer, J. Enders and U. Schimank (2007) On the way to new public management? The governance of university systems in England, the Netherlands, Austria and Germany. In: D. Jansen (Ed.), New Forms of Governance in Research Organisations: Disciplinary Approaches, Interfaces and Integration (Dordrecht: Springer).

5. P. Scott (1993) The Meanings of Mass Higher Education (Buckingham: Open University Press).

6. T. Tapper and D. Palfreyman (Eds) (2005) Understanding Mass Higher Education: Comparative Perspectives on Access (London: Routledge).

7. M. Power (1997) The Audit Society: Rituals of Verification (Oxford: Oxford University Press).

8. R. Richardson and T. Smalling (2004) Accountability and governance. In: J. Burke (Ed.), Achieving Accountability in Higher Education: Balancing Public, Academic, and Market Demands (San Francisco: Wiley), pp. 55-77.

9. B. Stensaker and L. Harvey (2011) Accountability in Higher Education: Global Perspectives on Trust and Power (London: Routledge).

10. A. Amaral, O. Tavares and C. Santos (2012) Higher education reforms in Europe: a comparative perspective of new legal frameworks in Europe. In: A. Curaj, P. Scott, L. Vlasceanu and L. Wilson (Eds.), European Higher Education at the Crossroads: Between the Bologna Process and National Reforms (Dordrecht: Springer).

11. D. Mabbett (2011) The regulatory rescue of the welfare state. In: D. Levi-Faur (Ed.), Handbook on the Politics of Regulation (Cheltenham: Edward Elgar).

12. S. Collini (2102) What Are Universities For? (Harmondsworth: Penguin).

13. D. Hicks (2012) Performance-based university research funding systems. Research Policy, 41(2), pp. 251-261.

14. M. Gibbons, C. Limoges, H. Nowotny, P. Scott, S. Schwartzman and M. Trow (1994) The New Production of Knowledge: The Dynamics of Science and Research in Contemporary Societies (London: Sage).

15. H. Nowotny, P. Scott and M. Gibbons (2001) Rethinking Science: Knowledge and the Public in an Age of Uncertainty (Cambridge: Polity Press). 
16. D. Watson, R.M. Hollister, S.E Stroud and E. Babcock (2011) The Engaged University: International Perspectives on Civic Engagement (London: Routledge).

17. E. Hazelkorn (2016) Contemporary debates part 1: theorising civic engagement. In: J. Goddard, E. Hazelkorn, L. Kempton and P. Vallance (Eds.), The Civic University: The Policy and Leadership Challenges (Cheltenham: Edward Elgar).

18. R. Florida, P. Adler and C. Mellander (2016) The City as Innovation Machine, Martin Prosperity Research: Working Paper Series (Rotman School of Management, University of Toronto), http://martinprosperity.org/media/2016MPIWP-002_The-City-as-Innovation-Machine_Florida-Adler-Mellander.pdf

19. A. Goodall (2009) Socrates in the Boardroom: Why Research Universities Should Be Led By Top Scholars (Princeton: Princeton University Press).

\begin{abstract}
About the Author
Peter Scott is Professor of Higher Education Studies at the UCL Institute of Education, UK. He is currently working on a comparative study of university governance across Europe at the Centre for Global Higher Education. Previously he was Vice-Chancellor of Kingston University and Professor of Education at the University of Leeds. His most recent book (with Jim Gallacher and Gareth Parry) is New Languages and Landscapes of Higher Education (Oxford University Press, 2016). $\mathrm{He}$ is chair of the Behavioural Sciences Section of the Academia Europaea.
\end{abstract}

